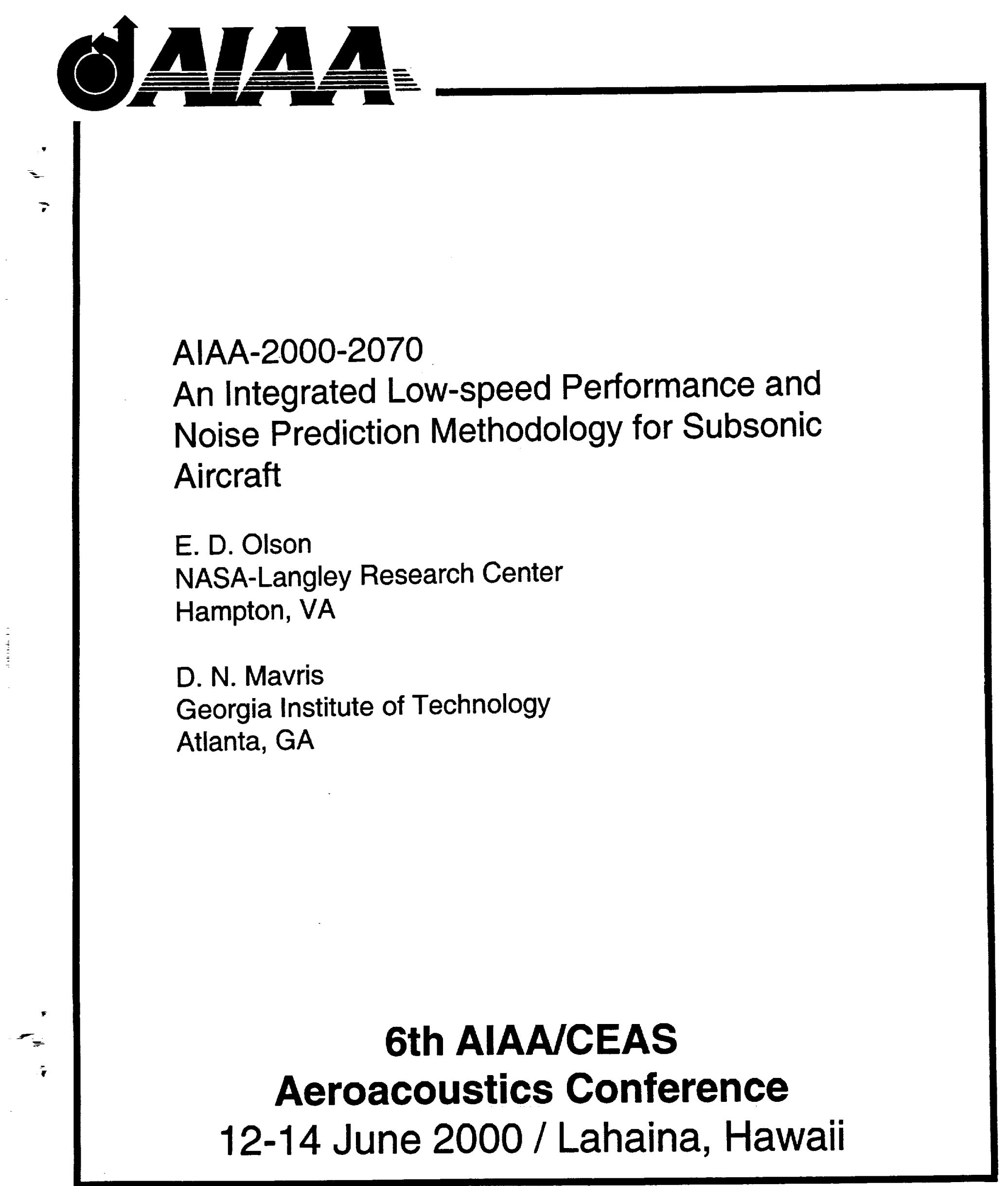



AIAA-2000-2070

\title{
AN INTEGRATED LOW-SPEED PERFORMANCE AND NOISE PREDICTION METHODOLOGY FOR SUBSONIC AIRCRAFT
}

\author{
E. D. Olson* \\ National Aeronautics and Space Administration \\ Langley Research Center \\ Hampton, VA 23681-2199 \\ D. N. Mavris ${ }^{+}$ \\ Department of Aerospace Engineering \\ Georgia Institute of Technology \\ Atlanta, GA 30332-0150
}

\begin{abstract}
An integrated methodology has been assembled to compute the engine performance, takeoff and landing trajectories, and community noise levels for a subsonic commercial aircraft. Where feasible, physics-based noise analysis methods have been used to make the results more applicable to newer, revolutionary designs and to allow for a more direct evaluation of new technologies. The methodology is intended to be used with approximation methods and risk analysis techniques to allow for the analysis of a greater number of variable combinations while retaining the advantages of physics-based analysis. Details of the methodology are described and limited results are presented for a representative subsonic commercial aircraft.
\end{abstract}

\section{Introduction}

Worldwide demand for air travel is expected to triple by 2015 ; studies have shown that meeting this demand will require twice as many aircraft than were available in 1995.' Today's aircraft are $20 \mathrm{~dB}$ quieter than the first jet-powered airplanes, but in the absence of further noise reduction technology, noise restrictions at the international, national and local levels may

\footnotetext{
* Aerospace Engineer, Member AIAA

+ Assistant Professor, Senior Member AIAA

Copyright ( 2000 by the American Institute of

Aeronautics and Astronautics, Inc. No copyright is asserted in the United States under Title 17, U.S. Code.

The U.S. Government has a royalty-free license to exercise all rights under the copyright claimed herein for Governmental Purposes. All other rights are reserved by the copyright owner.
}

constrain the capacity of the global aviation system to meet the growing demand.? In response to these issues, NASA has set an aggressive goal of $20 \mathrm{~dB}$ reduction in the perceived noise levels of subsonic aircraft by the year 2017." Achieving this goal will require innovative noise reduction technologies combined with a multidisciplinary, systems approach to aircraft design.

\section{Concurrent Design}

The solid curves in Figure 1 show the evolution of design knowledge, freedom and cost committed during a typical aircraft design and development process. The traditional design stage delineations are indicated at the bottom of the figure. The goal of concurrent design is to shift the knowledge, cost, and freedom curves as shown by the arrows in Figure I. Adopting a multidisciplinary design and analysis environment and improving the fidelity of the analyses in the early stages of the design process results in a more rapid increase in design knowledge than in the traditional design process. By limiting the number of choices made about the design until more knowledge can be obtained, the design freedom can be retained for a greater portion of the process so that the greatest drop-off occurs at the later stages. As result of these changes, the committed cost is kept low until the bulk of the decisions are made, later in the process.

The use of physics-based analysis early in the design process, instead of the traditional empirical methods, can improve the process by providing higherfidelity results, by producing analyses which are applicable to newer, revolutionary designs and by offering the ability to directly assess the benefits of new technologies. Use of physics-based analysis tools 


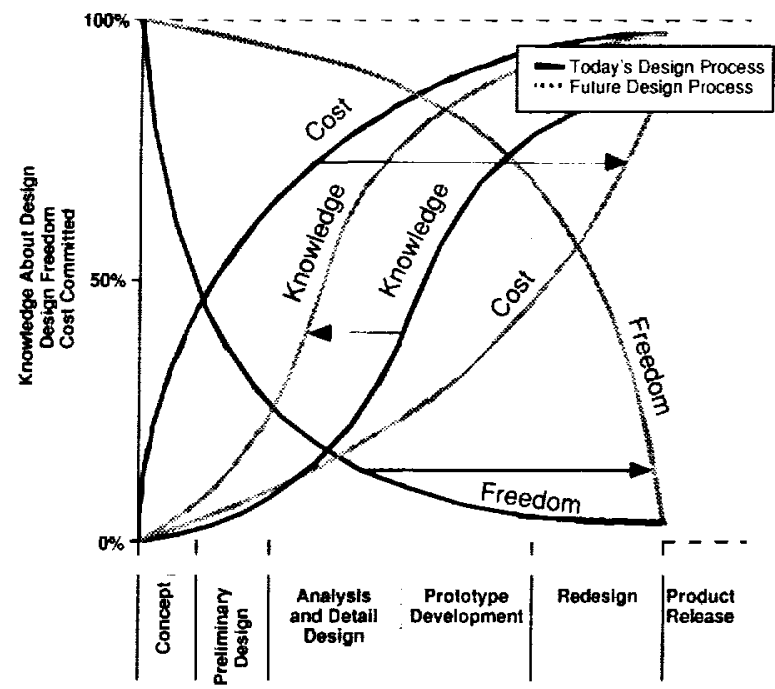

Figure 1: Evolution of design knowledge, design freedom, and cost committed during the design and development process ${ }^{4}$

during conceptual design would be a important step in the realization of the goals of concurrent design. Unfortunately, the greater computational time required by physics-based analysis methods has made their use impractical for conceptual design studies where many rapid computations are required and where design knowledge is limited.

\section{Approximation Techniques}

One way to enable the use of physics-based analysis tools in early design stages is through the use of approximation techniques. In this method, a metamodel is created which retains the overall properties of the high-fidelity analysis, but can be executed much more quickly. Figure 2 illustrates how a metamodel can be used in the same way as empiricallybased noise prediction methods. The first step is to apply the approximation technique to the physics-based noise prediction method to create a metamodel. The metamodel is then used in all subsequent design studies so that rapid evaluations can be made. Multiple metamodels can be created for the various disciplines such as aerodynamics, structures, propulsion, and stability and control, and can be integrated at the system level. The metamodels provide the various responses necessary to compute the overall system-level performance and economics of the aircraft, as well as constraints on handling qualities and environmental impact.

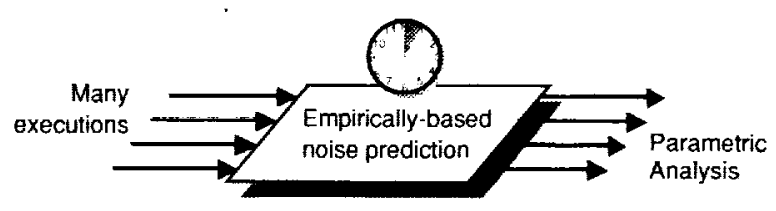

(a) traditional conceptual design approach

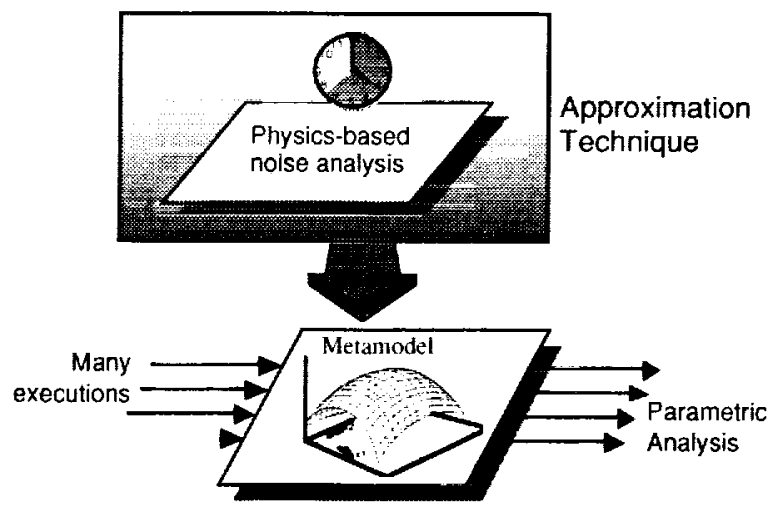

(b) use of approximation techniques

Figure 2: Using approximation techniques to create a metamodel

The most commonly used approximation method is response surface methodology (RSM), wherein a simple polynomial response surface equation (RSE) is used to represent the output from one or more analyses:

$$
R=b_{0}+\sum_{i=1}^{n} b_{i} x_{i}+\sum_{i=1}^{n} b_{i i} x_{i}^{2}+\sum_{i=1}^{n-1} \sum_{j=i+1}^{n} b_{i j} x_{i} x_{j}
$$

where $R$ is the value of the output or response, $x_{i}$ are the design variables or factors, and $b_{i}$ and $b_{i j}$ are the polynomial coefficients's. The coefficients of the equation are determined using regression techniques. A useful technique for finding the coefficients is design of experiments (DOE), which is a method for obtaining maximum regression information from a limited subset of factor combinations. DOE is used to obtain a set of factor combinations at which the analysis should be performed. $^{6}$

\section{Noise Risk Analysis}

An airframe manufacturer is typically required to guarantee to a customer that its aircraft will not exceed maximum allowable community, interior, and ramp noise levels. In addition, an airline may request compliance with restrictions at specific airports at 
which the airline plans to operate the airplane. These guarantees are often a very important factor in competition among airframe and engine manufacturers.

Unfortunately, it is currently impossible to predict precisely the measured noise levels of an aircraft design due to the inherent uncertainties in the actual operational environment, limited analysis model fidelity, and the technology risk that are always present during any design cycle. For a completely new airplane design with new engines, a decision on airplane goahead and customer guarantees usually must be made at early design stages when the uncertainties are high. To account for the uncertainty in the final noise levels, the aircraft must be designed so that the nominal noise prediction is sufficiently below the guarantee levels to reduce the design risk to an acceptable level. Increased fidelity in noise analysis early in the design process could reduce the overall uncertainty, allowing for smaller initial margins for the same design risk.

\section{Methodology}

An integrated aircraft/engine performance and noise prediction methodology has been developed which can be used within the framework of RSM and risk analysis to perform conceptual-level design studies while incorporating physics-based noise analysis methods. The advantages of physics-based analysis methods can be exploited while still retaining the flexibility to analyze many different design variable combinations.

The current analysis process is shown in Figure 3. To predict community noise levels, a wide variety of independent programs with different data handling procedures and different output formats are used; for this reason, it is imperative that the programs be integrated to minimize the amount of repetitive work required by the designer. A well-integrated system can be made to run overnight or over weekends to make efficient use of the amount of time available to the designer. Rather than attempt to create a monolithic combination of computer routines, the individual programs have been kept intact in a tightly-coupled system. Each program is used in combination with "wrappers": pre- and post-processing utilities which provide the necessary information from a central design information database. By maintaining the boundaries of each separate program, the system is kept flexible for replacing the programs as newer methods become available. The individual programs are described in the following sections:

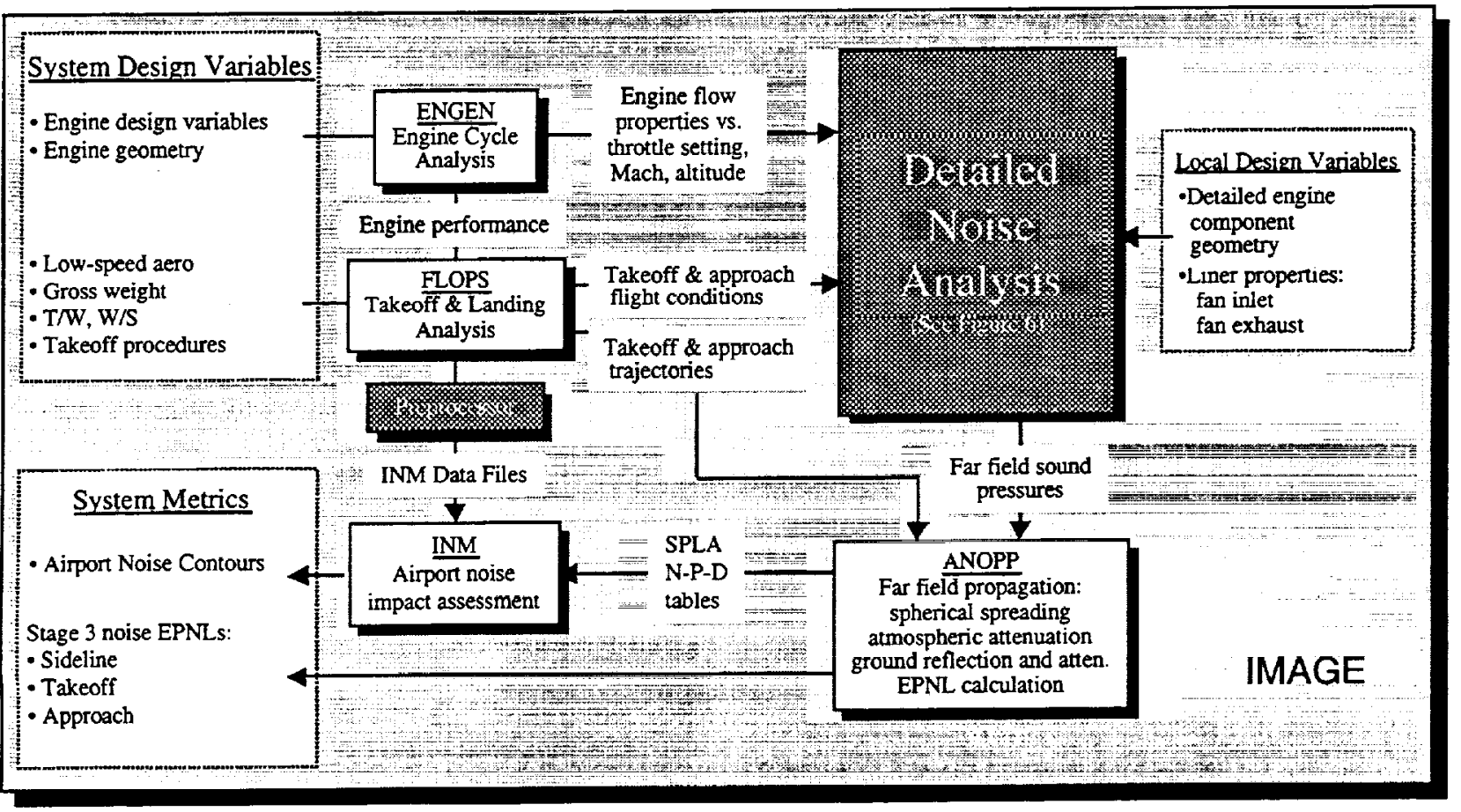

Figure 3: Overall flow chart for analysis process and data flow

3

American Institute of Aeronautics and Astronautics 


\section{Engine and Aircraft Performance}

Prediction of the aircraft noise levels at various measuring points on the ground begins with an accurate determination of the aircraft's trajectory, i.e., the aircraft's location, attitude, velocity, operating conditions, etc., as a function of time.

The first step in the analysis process is to compute the performance of the engine using the engine cycle analysis \& design module of the Flight Optimization System (FLOPS). ${ }^{7}$ FLOPS is a multidisciplinary suite of computer routines for mission analysis and optimization of aircraft. The engine cycle analysis module is based on QNEP, which is a modified version of the Navy Engine Performance Computer Program (NEPCOMP. ${ }^{8-10}$ Engine cycle definition decks are provided for turbojets, turboprops, mixed flow turbofans, separate flow turbofans, and turbine bypass engines. Analysis is one-dimensional, using scaled component maps input by the user. Compressor and turbine blade counts and geometry are estimated from simple mean-line analysis and empirical correlations.

Using the computed engine performance and the aircraft low-speed aerodynamics information, the takeoff and landing performance field lengths and trajectories are then computed using the FLOPS takeoff and landing module. Performance is computed for takeoff and aborted takeoff, at all-engine and oneengine-out conditions. The balanced field length and FAR takeoff field length are computed. FAR 25 required available engine-out climb gradients are enforced for both takeoff and missed approach. The post-processor extracts the takeoff and landing flight paths, and the flight conditions and engine operating conditions at sea level static, sideline, cutback and approach conditions.

\section{Engine Geometry Post-processing}

Since the engine cycle analysis methodology in FLOPS uses one-dimensional analysis and engine component maps, little geometrical information is needed to compute the engine performance. The cycle analysis module does, however, contain routines for estimating the various component geometries, weights, and flow paths. FLOPS provides a simplified estimate of the engine geometry, which is used as the starting point for developing a more detailed description of the geometry for use in the higher-fidelity analysis methods which follow. Figure 4 shows the evolution of the

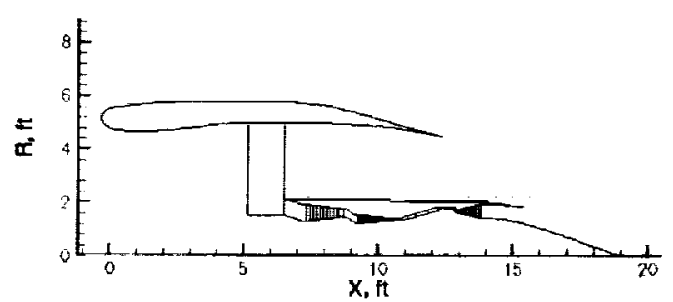

(a) output from FLOPS engine cycle module

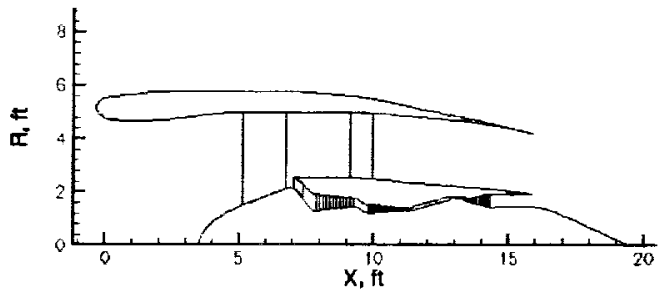

(b) after post-processing by geometry utility

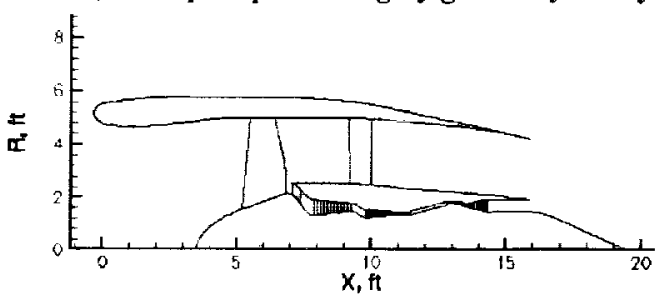

(c) after fan blade design

Figure 4: Evolution of engine flow path geometry

engine geometry information. Figure 4(a) shows the geometry as defined in the FLOPS output. Engine components are represented as block diagrams. Figure 4 (b) shows the geometry after it is processed by the engine geometry processing utility. The fan rotor and stator aspect ratios, rotor-stator spacing and hub ramp angle are changed based on user input; a nose cone is added; the nacelle is extended to make the core and bypass jet exhausts coplanar; and the nacelle outer surface is adjusted to enforce slope and curvature limits. Finally, Figure 4(c) shows the engine crosssection after the fan blade design has been performed as described in the next section. Another utility can be used to produce three-dimensional plotting information in TECPLOT format (Figure 5).

\section{Fan Preliminary Design}

In order to calculate fan noise, the fan blade geometry must be defined, and the fan flow field must be computed at each flight condition. First, the axialflow compressor spanwise conceptual design code CSPAN $^{11-12}$ is used to find the design velocity triangles for the fan rotor and stator blades. CSPAN uses a rapid approximate design methodology based on the isentropic simple radial-equilibrium equations. Design 


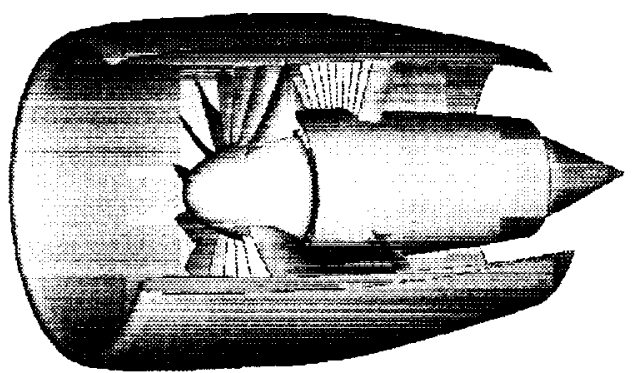

Figure 5: Three-dimensional engine geometry plot

point pressure loss and design inlet and exit blade angles are computed using empirical correlations. The CSPAN program is used in conjunction with an optimizer, DONLP2 ${ }^{13}$, to find the optimum radial distribution of intrastage tangential velocity. DONLP2 uses sequential equality-constrained quadratic programming with an active set technique. The optimizer seeks to minimize the value of

$$
F=\sum_{i=1}^{n}\left(\pi_{i}-\pi_{\text {des }}\right)^{2}
$$

where $\pi_{d e s}$ is the design fan pressure ratio and $\pi_{i}$ is the actual pressure ratio at each radial station. The problem is subject to the constraints of maximum rotor diffusion ratio, stator diffusion ratio, stator inlet Mach number, rotor turning, and stage reaction at each radial station. The rotor exit tangential velocities at four radial stations are used as the design variables in the optimization.

Using the computed design inlet and exit blade angles, rotor and stator blade sections are created using polynomial curves for the blade mean-line angle and thickness distributions as a function of mean-line distance. The method used is similar to that of reference 14 .

\section{Noise Analysis}

The noise analysis methods have been selected to meet certain criteria to be appropriate for use in this study: (1) the method must be applicable to the subsonic commercial aircraft and high-bypass ratio engines; (2) the method must be based primarily on the laws of physics, with empiricism limited to secondary aerodynamic phenomena such as fan blade wake distributions and jet plume aerodynamics; and (3) the entire analysis for one configuration at one flight condition must run in a reasonable time--on the order of two hours or less. Even though the goal is to incorporate higher-fidelity analysis methods into the conceptual design process, there is still an upper limit to the analysis time which can be tolerated while still maintaining the ability to examine a reasonably large design space.

A layout of the detailed noise analysis block is shown in Figure 6. Since the fan, jet, airframe etc. noise source components are independent, they can be computed in parallel for more rapid computation.

Fan Tone Noise The first step in computing the fan noise consists of determining the fan flow field characteristics at each flight condition using the MERIDLN and PCSTAGE codes. MERIDLN ${ }^{15}$ computes the subsonic or transonic fan flow solution on the hub-shroud midchannel stream surface, using a nonlinear finite-difference solution of the stream function. Using the through flow solution, PCSTAGE ${ }^{16,17}$ computes the blade-to-blade flow field using an steady, compressible, integral equation (panel) method. The analysis is two-dimensional but includes the three-dimensional effects of stream sheet thickness variation, radius change and blade row rotation. The two codes, used in combination, create a quasi-three dimensional representation of the fan flow field. The fan rotor/stator interaction tone noise and coupling to the duct are computed using the V072 computer program. ${ }^{18}$ V072 estimates the blade wake velocity deficit using empirical relationships. The tones from the interactions of the rotor blade wakes with the bypass and core stator vanes are then computed using a constant-area annular duct and flat plate stator cascade model. Output consists of modal amplitudes for the cut-on duct modes. Using the source information from V072, the duct propagation and radiation to the far field are computed using the Eversman inlet and exhaust finite element radiation codes ${ }^{19}$. The Eversman suite of codes consists of a mesh generator for creation of computational meshes for the inlet and exhaust fan ducts, a potential flow solver for solution of the mean flow equations, and a hybrid finite-element and waveenvelope radiation code for solution of the duct radiation equations for an input modal distribution at the source plane.

Jet Noise Jet noise is computed using the original $M^{*} G^{*} B$ computer program. ${ }^{2 n}$ Initially, $M * G * B$ predicts the jet plume mean flow field and turbulence intensity using an extension of Reichardt's semi-empirical method. Using the predicted flow field, Lighthill- 


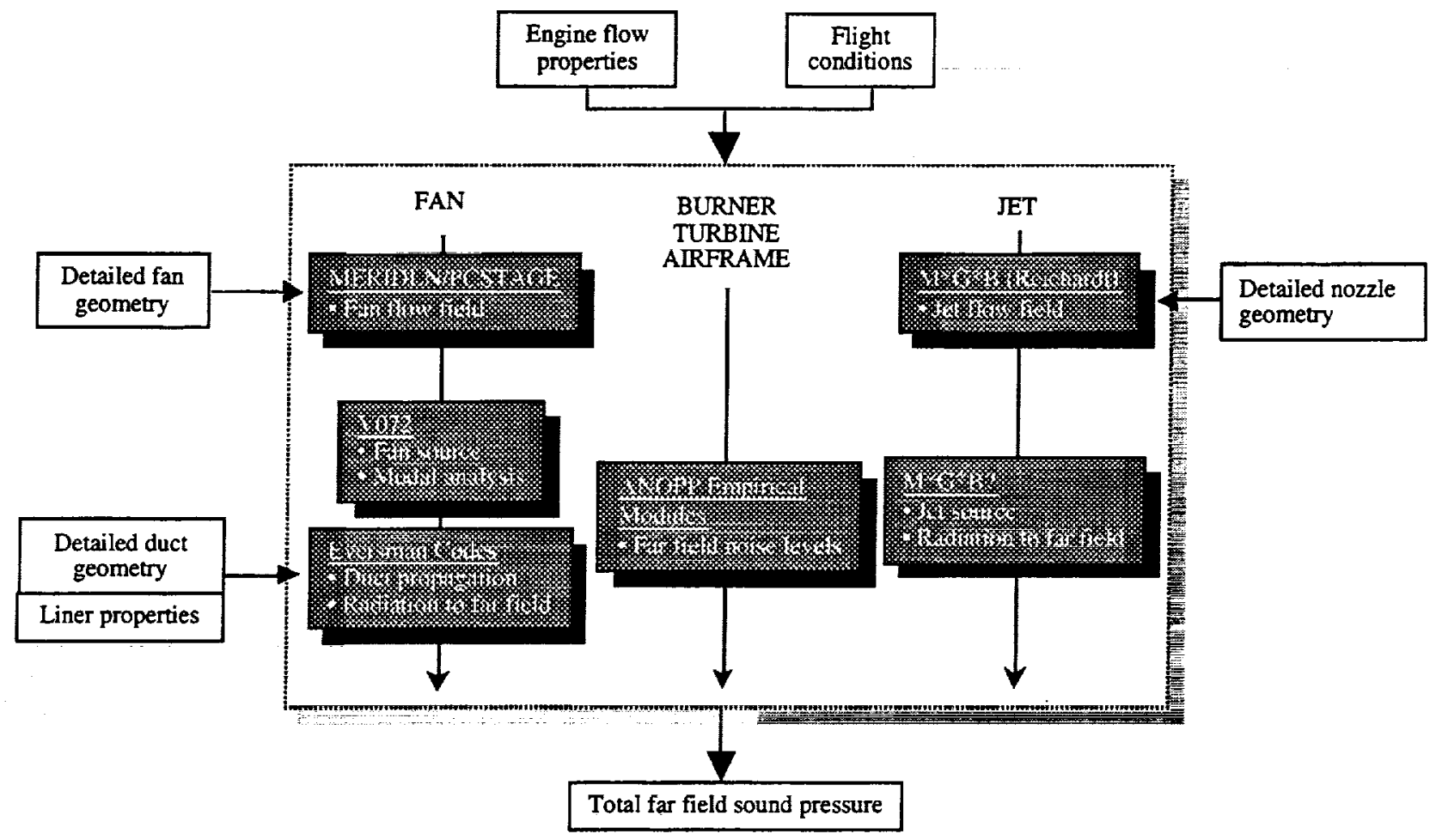

Figure 6: Detailed noise analysis block

Ribner theory is used to predict the noise generated by turbulent fluctuations in the mixing regions, combined with Lilley's equation to account for propagation of the near field sound through the inhomogeneous jet plume. Output from $\mathrm{M}^{*} \mathrm{G} * \mathrm{~B}$ consists of the predicted jet plume flow field and the far field sound pressure level as a function of frequency and directivity angle.

Qther Sources Suitable physics-based methods for additional components of the total sound field such as airframe, core, and turbine noise which satisfy the constraints on applicability and computation time do not appear to be available. These sources are currently modeled using empirical methods. The methodology has been assembled in such a manner, however, that if suitable methods become available in the future, they can be inserted into the analysis without difficulty.

\section{Propagated noise levels}

Output from the detailed noise analysis block consists of the total far field noise spectrum as a function of directivity angle, at each of the flight conditions in the takeoff and landing flight paths. The far field source noise levels and the takeoff and landing flight paths are passed to the Aircraft Noise Prediction
Program (ANOPP) ${ }^{21,22}$ for propagation to the defined observer locations. ANOPP is a computer program used to predict aircraft noise levels using empirical source component methods, but the propagation, atmospheric attenuation and ground effects routines are based on physical laws. ANOPP computes the effective perceived noise levels (EPNL) and the Aweighted sound pressure level (SPLA) at each of the FAR Part 36 sideline, takeoff, and approach observer locations (Figure 7). Noise levels can also be computed using a set of steady flyover flight procedures for creation of noise-power-distance (NPD) tables.

Airport community noise levels are computed

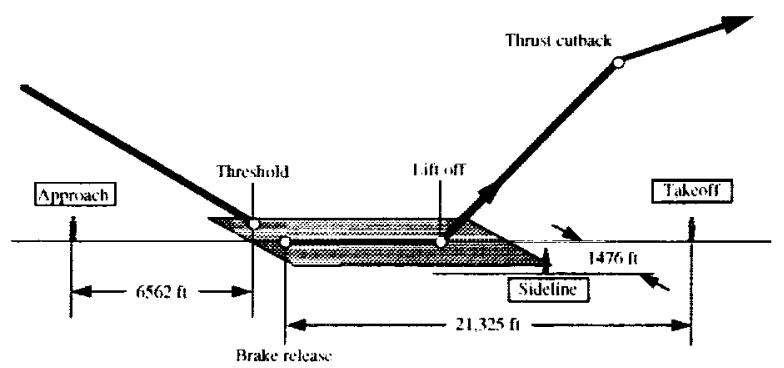

Figure 7: FAR 36, Stage 3 observer locations 
using the FAA Integrated Noise Module (INM) computer program ${ }^{23}$, which is widely used for FAR Part 150 noise compatibility planning and FAA Order 1050 environmental assessments. INM uses the NPD tables from ANOPP and aircraft performance data from FLOPS to generate airport noise contours for singleevent noise exposure (SENEL). In addition, cumulative day-night exposure levels (DNL) can be computed for a given airport using a defined distribution of flight procedures and numbers of operations for different aircraft in the fleet.

\section{Selected Results}

At this time, only limited analysis results are available from the assembled methodology. This section contains selected results for the aircraft and engine shown in Figure 8. The aircraft is a 300passenger, twin-engine civil transport with a design gross weight of 540,000 pounds and a nominal design range of 6500 nautical miles. The aircraft is powered by a separate-flow, two-spool high-bypass ratio turbofan engine with a baseline thrust of 80,000 pounds, a bypass ratio of 8 , and a geared low-speed fan with a pressure ratio of 1.4 .

Engine performance, takeoff and landing flight performance, and takeoff noise levels have been computed for this configuration. The computed flight paths are shown in Figure 9 for takeoff and approach, using FAR 36 noise certification procedures. The blade sections for the fan rotor at the hub, mid-channel, and tip stations are shown in Figure 10 as assembled by the preliminary fan design methods. These blade sections represent a starting point for the surface definition and have not been optimized to achieve true controlleddistribution sections. Figure 11 shows the computed fan streamlines in the meridional plane, as computed by MERIDLN, for the sideline flight condition. The computed inlet-radiated rotor-stator interaction tone acoustic field is shown in Figure 12 for the $m=6$ circumferential mode at twice the blade passing frequency (BPF). The jet mean flow velocity and turbulence intensity fields are shown in Figure 13.

\section{Concluding Remarks}

The methodology described in this paper represents an implementation of an analysis system which can be used in conjunction with approximation methods and risk analysis techniques to conduct conceptual-level design studies using physics-based noise analysis. The
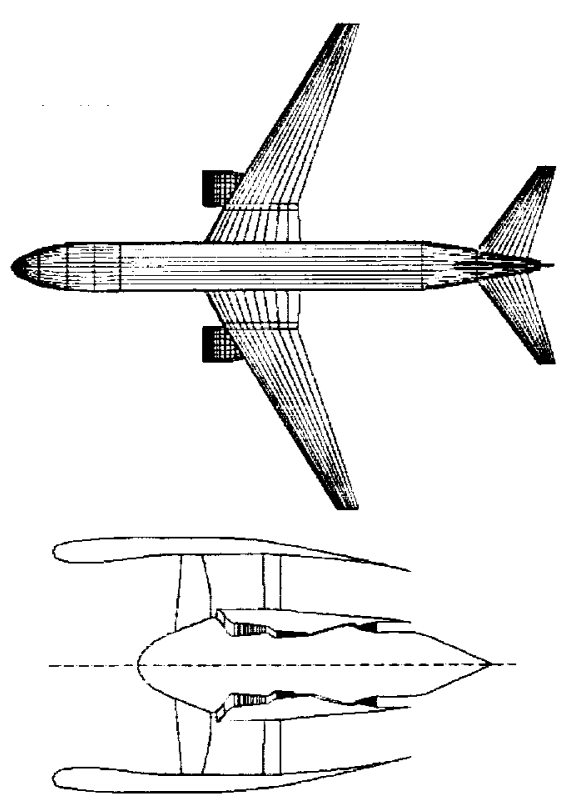

Figure 8: Representative aircraft and engine

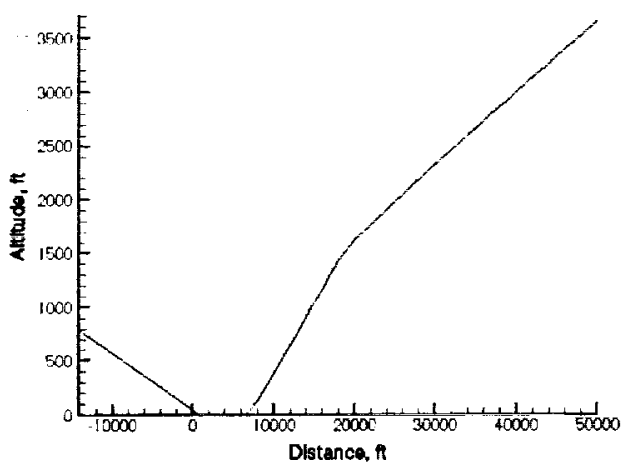

Figure 9: Takeoff and landing flight paths

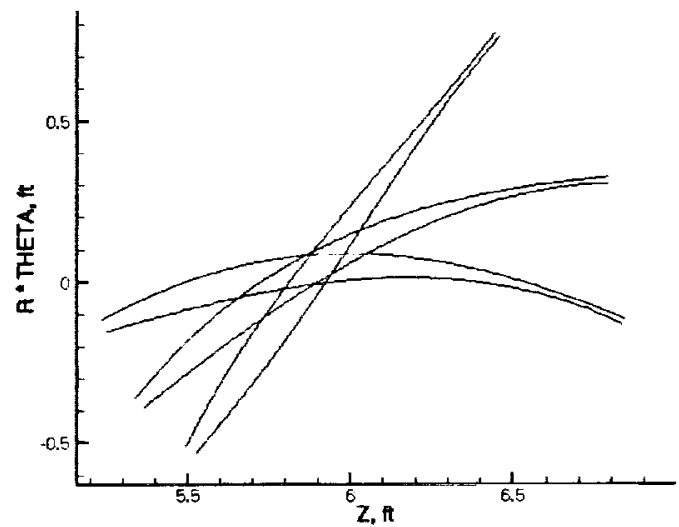

Figure 10: Baseline fan rotor blade sections 


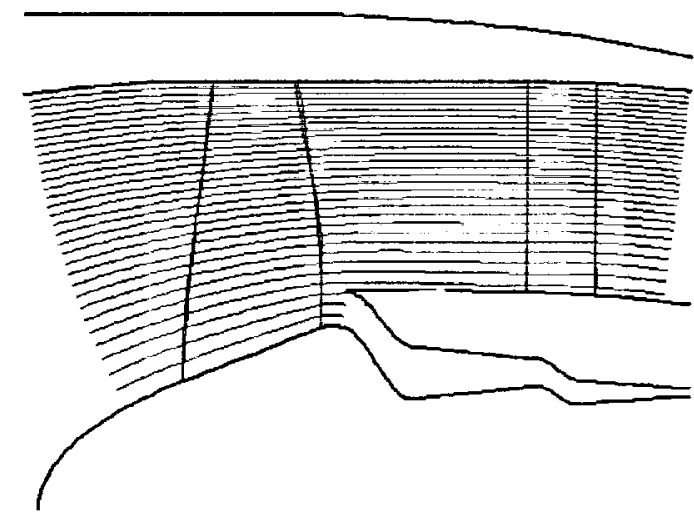

Figure 11: Computed fan through-flow streamlines, sideline fight condition

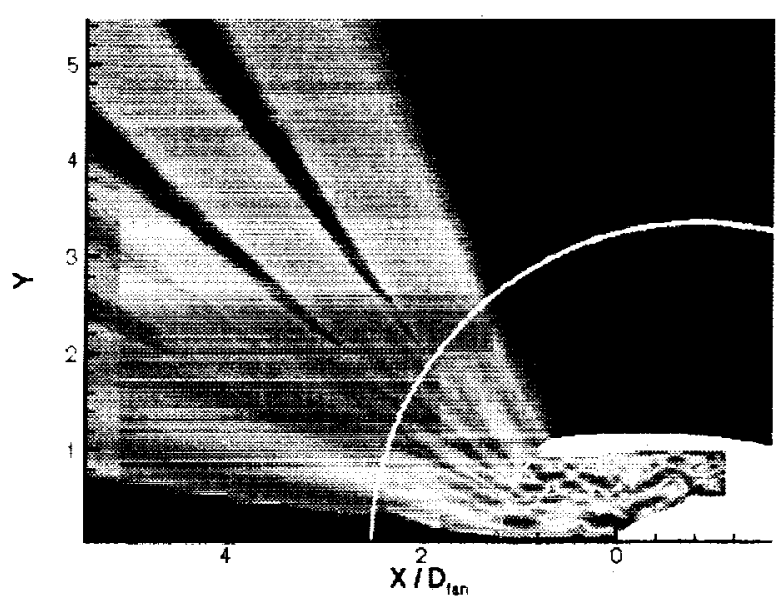

Figure 12: Computed fan inlet rotor-stator interaction tone SPL contours, sideline flight condition $(f=2 B P F$,

$$
m=-6 \text { ) }
$$

various analysis methods and utilities have been integrated so that data is passed automatically from one program to another and the entire analysis can be carried out without manual data conversion and program execution by the designer. Analysis methods have been kept physically separated, with pre- and postprocessors providing the necessary data conversion; in this way, new methods can be integrated into the methodology more easily than if a monolithic architecture had been used.

Further improvements to the methodology may involve (1) integrating the analysis methods into a computer architecture that provides a graphic user

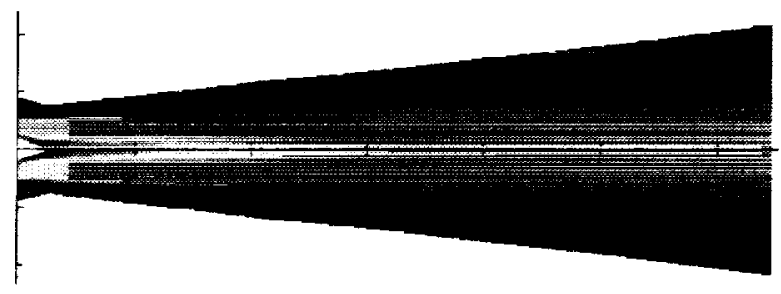

(a) mean velocity contours

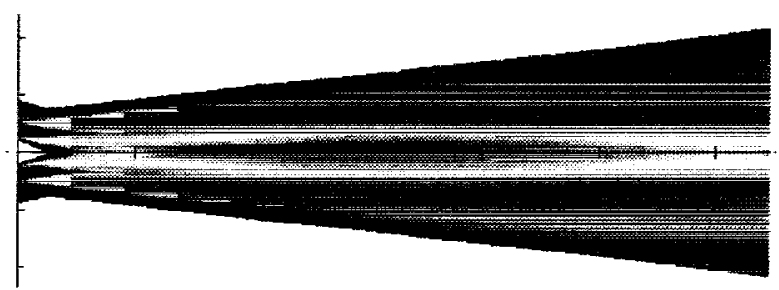

(b) turbulence intensity contours

Figure 13: Computed jet plume aerodynamics, baseline configuration, sideline flight condition

interface and simplified handling of data and analysis flow; (2) adding a fan blade boundary layer analysis method to replace the empirically-computed blade wake velocity distributions in V072; and (3) computing the jet plume flow field using thin-layer Navier-Stokes CFD to replace the empiricism of Reichardt's method.

\section{References}

1. Baugham, Steven L., et aI: Year 2015 Aircraft Emission Scenario for Scheduled Air Traffic. NASA CR-1998-207638, March, 1998.

2. Willshire, W. L., Jr., and Stephens, D. G.: Aircraft Noise Technology for the $21^{\text {st }}$ Century. NOISECON '98, Ypsilanti, Michigan, April 5-8, 1998.

3. Three Pillars for Success: NASA's Response to Achieve the National Priorities in Aeronautics and Space Transportation. Office of Aeronautics and Space Transportation Technology, National Aeronautics and Space Administration, March 1997.

4. Mavris, D. N., DeLaurentis, D. A., Bandte, O., and Hale, M. A.: A Stochastic Approach to Multidisciplinary Aircraft Analysis and Design. 36 AIAA Aerospace Sciences Meeting \& Exhibit. Reno, NV, January 12-15, 1998.

5. Khuri, A. J., and Cornel, J. A.: Response Surface Methodology. Virginia Commonwealth University, 
Boston, MA, 1971.

6. Box, G. E. P., Hunter, W. G., and Hunter, J. S.: Statistics for Experimenters, An Introduction to Design, Analysis, and Model Building. John Wiley \& Sons, New York, 1978.

7. McCullers, L. A.: FLOPS User's Guide Ver. 5.94. NASA Langley Research Center, Hampton, VA, July 14, 1999.

8. Caddy, Michael J. and Shapiro, Stanley R.: NEPCOMP - The Navy Engine Performance Computer Program, Version I, NADC-74045-30, April 1975.

9. Fishbach, Laurence H. and Caddy, Michael J.: NNEP - The Navy NASA Engine Program. NASA TM X-71857, December 1975.

10. Geiselhart, Karl A.; Caddy, Michael J.; and Morris, Shelby J., Jr.: Computer Program for Estimating Performance of Air-Breathing Aircraft Engines. NASA TM 4254, May 1991.

11. Bryans, A. C., and Miller, M. L.: Computer Program for Design of Multistage Axial-Flow Compressors. NASA CR-54530, 1967.

12. Glassman, A. J., and Lavelle, T. M.: Enhanced Capabilities and Modified Users Manual for AxialFlow Compressor Conceptual Design Code CSPAN. NASA TM-106833, January, 1995.

13. Spellucci, P.: An SQP Method for General Nonlinear Programs Using Only Equality Constrained Subproblems. Math. Prog. 82, 1998, 413-448.

14. Sanger, N. L.: The Use of Optimization Techniques to Design Controlled Diffusion Compressor Blading. Transactions of the American Society of Mechanical Engineers 105, April, 1983, 256-264.

15. Katsanis, T., and McNally, W. D.: Revised FORTRAN Program for Calculating Velocities and Streamlines on the Hub-Shroud Midchannel Stream Surface of an Axial-, Radial-, or Mixed-Flow Turbomachine or Annular Duct, I--User's Manual. NASA TN D-8430, March, 1977.

16. McFarland, E. R.: An Integral Equation Solution for Multi-Stage Turbomachinery Design Calculations. ASME Paper 93-GT-4I, 1993.

17. McFarland, E. R.: Use of Preliminary Design Methods in the Analysis of Multi-Stage Turbomachinery. NASA CP-3282, Vol. II, 1994.

18. Topol, D. A., and Mathews, D. C.: Rotor Wake/Stator Interaction Noise Prediction Code, Technical Documentation and User's Manual. United Technologies Corporation, Pratt \& Whitney, East Hartford, CT, April, 1993.
19. Roy, I. D., and Eversman, W.: Development of the Inlet and Aft Fan Duct Acoustic Radiation Codes. Informal Report to NASA Lewis under NASA Grant NASA NAG3 1678, April, 1996.

20. Gliebe, P. R., Motsinger, R. E., and Sieckman, A.: High Velocity Jet Noise Source Location and Reduction, Task 6 Supplement--Computer Programs: Engineering Correlation $\left(\mathrm{M}^{*} \mathrm{~S}\right)$, Jet Noise Prediction Method and Unified Aeroacoustic Prediction Model $\left(M^{*} G^{*} B\right)$ for Nozzles of Arbitrary Shape. FAA-RD-76-79, VIa, March, 1979.

21. Zorumski, W. E.: Aircraft Noise Prediction Program Theoretical Manual. NASA TM-83199, February, 1982.

22. Gillian, R. E.: Aircraft Noise Prediction Program User's Manual. NASA TM-84486, January, 1983.

23. Federal Aviation Administration: Integrated Noise Model (INM) Version 5.0 User's Guide. FAAAEE-95-01, August, 1995. 
